\title{
Integrin $\beta 1$ Gene Therapy Enhances in Vitro Creation of Tissue-Engineered Cartilage Under Periodic Mechanical Stress
}

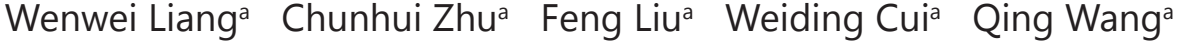 \\ Zhefeng Chen ${ }^{\mathrm{a}}$ Qijia Zhou ${ }^{\mathrm{b}}$ Shun Xua Chenjun Zhai ${ }^{\mathrm{a}}$ Weimin Fan ${ }^{\mathrm{a}}$
}

aDepartment of Orthopedics, The First Affiliated Hospital of Nanjing Medical University, Nanjing,
'Department of Orthopedics, Funing People Affiliated Hospital of Nantong University, Yancheng, China

\section{Key Words}

Periodic mechanical stress - Integrinß1 - Up-regulation • Chondrocyte proliferation • Matrix synthesis

\begin{abstract}
Background/Aims: Periodic mechanical stress activates integrin $\beta 1$-initiated signal pathways to promote chondrocyte proliferation and matrix synthesis. Integrin $\beta 1$ overexpression has been demonstrated to play important roles in improving the activities and functions of several non-chondrocytic cell types. Therefore, in the current study, we evaluated the effects of integrin $\beta 1$ up-regulation on periodic mechanical stress-induced chondrocyte proliferation, matrix synthesis and ERK1/2 phosphorylation in chondrocyte monolayer culture, and evaluated the quality of tissue-engineered cartilage constructed in vitro under periodic mechanical stress combined with integrin $\beta 1$ up-regulation. Methods and Results: Our results revealed that under periodic mechanical stress, pre-treatment with integrin $\beta 1$-wild type vector significantly enhanced chondrocyte proliferation and matrix synthesis and promoted ERK1/2 phosphorylation in comparison to mock transfectants. Furthermore, when chondrocytes were seeded in PLGA scaffolds, more accumulated GAG and type II collagen tissue were detected after Lv-integrin $\beta 1$ transfection compared with sham controls exposed to periodic mechanical stress. In contrast, in the Lv-shRNA-integrin $\beta 1$ group, the opposite results were observed. Conclusion: Our findings collectively suggest that in addition to periodic mechanical stress, integrin $\beta 1$ up-regulation in chondrocytes could further improve the quality of tissueengineered cartilage.
\end{abstract}

W. Liang and C. Zhu contributed equally to this work.

Weimin Fan

KARGER 125
Department of Orthopedics, The First Affiliated Hospital of Nanjing Medical University, 300 Guang Zhou Road, Nanjing 210029, (China)

Tel. +86-25-83718836-6780, E-Mail liangwenwei321@sina.com 


\section{Cellular Physiology Cell Physiol Biochem 2015;37:1301-1314 \begin{tabular}{ll|l} 
DOI: 10.1159/000430253 & $\begin{array}{l}\text { O } 2015 \text { The Author(s). Published by S. Karger AG, Base } \\
\text { www.karger.com/cpb }\end{array}$ \\
\hline
\end{tabular} \\ Liang et al.: Integrin $\beta 1$ Enhances Tissue-Engineered Cartilage}

\section{Introduction}

Periodic mechanical stress has been shown to significantly enhance the quality of tissue-engineered cartilage [1-3]. Pingguan-Murphy and Nawi demonstrated that cyclic mechanical loading promoted glycosaminoglycan synthesis by bovine chondrocytes cultured in an agarose gel [4]. A study by Wang et al. revealed that under conditions of cyclic compression, the expression of type II collagen and aggrecan were significantly increased in rabbit chondrocytes [1-3]. The mechanisms by which chondrocytes sense and respond to periodic mechanical stress were also investigated. The MAPK signal cascade, especially ERK1/2 activity, has been proven to be associated with the biological effects induced by periodic mechanical stress in chondrocytes $[5,6]$. Our previous studies demonstrated that periodic mechanical stress could activate three signaling pathways converging on ERK1/2: integrin $\beta 1$-Src-Rac1-FAK-Tyr ${ }^{576 / 577}$-ERK1/2, integrin $\beta 1$-FAK-Tyr ${ }^{397}$-ERK1/2 and integrin $\beta 1$-Src-PLC $\gamma 1$-ERK1/2 to promote chondrocyte proliferation and matrix synthesis [7-10].

Integrin is the main receptor that plays an important role in mechanosensing and signal transduction [11-13]. Many studies have shown that integrin inhibition blocks the biological effects induced by mechanical stimulation in chondrocytes [14-16]. The work of Chowdhury et al. demonstrated that when integrin $\alpha 5 \beta 1$ was attenuated by GRGDSP in articular chondrocytes, dynamic compression-induced ${ }^{35} \mathrm{SO} 4$ and $\left[{ }^{3} \mathrm{H}\right]$ thymidine were significantly reduced [17]. We previously observed that pretreatment of chondrocytes with blocking antibodies against integrin $\beta 1$ resulted in blockage of periodic mechanical stress-stimulated up-regulation of chondrocyte proliferation and matrix synthesis as well as ERK1/2 phosphorylation [9]. Furthermore, when subjected to numerous non-mechanical stimuli, integrin abolition also affected many cellular behaviors and functions in chondrocytes [18, 19].

As integrin $\beta 1$ inhibition markedly reduces the activities and functions of chondrocytes, this raised the possibility that integrin $\beta 1$ overexpression could elevate chondrocyte activity. Reviewing the past literature, we found no reports concerning the relationship between integrin $\beta 1$ up-regulation and cellular response of chondrocytes. However, in several nonchondrocytic cell types, integrin up-regulation resulted in a significant improvement in cellular activities. Liu et al. found that integrin $\beta 4$ overexpression was able to accelerate wound repair by promoting proliferation of airway epithelial cells [20]. Hu et al. discovered that when integrin $\alpha 2$ was overexpressed in hBMSCs from patients with senile osteoporosis, proliferation and osteogenic differentiation of hBMSCs were both significantly increased, accompanied by elevated ERK1/2 phosphorylation [21]. Furthermore, an earlier study in vascular smooth muscle cells revealed that either subjecting the cells to cyclic stretching or forcing expression of integrin $\alpha v \beta 3$ could abolish Ox-LDL-induced cytoskeleton disruption and apoptosis [22]. Thus, we speculated that in chondrocytes subjected to periodic mechanical stress, integrin $\beta 1$ over-expression would further promote chondrocyte proliferation and matrix synthesis accompanied by enhanced ERK1/2 phosphorylation.

Above all, the main aim of the present study was to explore whether, in chondrocytes under periodic mechanical stress, integrin $\beta 1$-overexpression could promote formation of higher quality tissue-engineered cartilage. After integrin $\beta 1$ up-regulation, we measured chondrocyte proliferation and matrix synthesis in 2D culture and assessed the quality of cartilage tissue formation in vitro under conditions of periodic mechanical stress, with a view to seeking convincing methods for constructing better quality tissue-engineered cartilage in future.

\section{Materials and Methods}

Materials

Two-week-old Sprague-Dawley (SD) rats of either sex were provided by the Animal Center of Nanjing Medical University. Fetal bovine serum was purchased from Hangzhou Sijiqing Biological Engineering 


\section{Cellular Physiology Cell Physiol Biochem 2015;37:1301-1314 \begin{tabular}{ll|l}
\hline DOI: 10.1159/000430253 & ( ) 2015 The Author(s). Published by S. Karger AG, Basel
\end{tabular} and Biochemistry Published online: October 19, 2015 www.karger.com/cpb \\ Liang et al.: Integrin $\beta 1$ Enhances Tissue-Engineered Cartilage}

Materials Co., Ltd (Zhejiang, China). DMEM-F12, trypsin, collagenase II, and type II collagen were obtained from Sigma (St Louis, MO). Cell Counting Kit-8 (CCK-8) was acquired from Beyotime Institute of Biotechnology (Jiangsu, China).,Anti-integrin $\beta 1$ rabbit antibody(CST Co., Ltd, \#4706S),anti-ERK1/2 rabbit antibody (CST Co., Ltd,, \#9102S), anti-phospho-ERK1/2 (Thr202/Tyr204) rabbit antibody(CST Co., Ltd, \#9101S), and HRP-goat anti-rabbit IgG were supplied by CST Co., Ltd (USA). Anti-collagen II rabbit antibody (Abcam, ab34712) and anti-aggrecan rabbit antibody (Abcam, ab36861) were supplied by Abcam (Cambridge, MA). HRP-conjuncted GAPDH antibody was supplied by Kang Chen (Shanghai, China, KC-5G5). ECL was purchased from Thermo Scientific (Waltham, MA). RNAiso Plus, PrimeScript RT Reagent Kit and SYBR Premix Ex Taq II were acquired from TaKaRa (Shiga, Japan). Integrin $\beta 1$ shRNA lentiviral particles, control shRNA lentiviral particles and Polybrene, as well as the GV287 vector, were supplied by Genechem (Shanghai, China). Wild-type integrin $\beta 1$ cDNA was subcloned into GV287 to force the expression of integrin $\beta 1$; a GFP-containing blank vector (GV287) served as the control.

A cell culture incubator (Heraeus BB 5060), an air-tight cell culture device and reciprocating pressure pump, barrier type pressure transducer, and inverted microscope equipped with a camera system were acquired from Heraeus (Hanau, Germany), Taixing Experimental Instrument Factory (Jiangsu, China), Tianjin Plastics Research Institute (Tianjin, China) and Olympus (Tokyo, Japan), respectively.

\section{Cell culture}

Chondrocytes were harvested using the method described by Séguin and Bernier [23]. Briefly, under sterile conditions, cartilage derived from the limb joints of two-week-old SD rats was harvested and sliced into $1 \mathrm{~mm}^{3}$ pieces. Tissues were digested with $0.25 \%$ trypsin at $37^{\circ} \mathrm{C}$ for $0.5 \mathrm{~h}$, followed by digestion with $0.2 \%$ collagenase II at $37^{\circ} \mathrm{C}$ for $4 \mathrm{~h}$. Cells were harvested by filtering with a 200 -mesh filter and cultured in DMEM-F12 medium supplemented with $10 \% \mathrm{FBS}$ in an incubator at $37^{\circ} \mathrm{C}$ with $5 \% \mathrm{CO}_{2}$. The cell population was purified by repeated adherence, and morphology was examined under an inverted phase-contrast microscope following staining with collagen type II according to the conventional ABC method. Secondgeneration cells were seeded onto glass slides $(25 \mathrm{~mm} \times 25 \mathrm{~mm})$ coated with type II collagen at a density of $10^{5}$ cells. Experiments were performed when cells reached $70-80 \%$ cell confluence.

\section{Scaffold preparation}

To promote cell attachment, the scaffolds (length of side $8 \mathrm{~mm}$, height $2 \mathrm{~mm}$ polylactide (PLA)polyglycolic acid (PGA) 9:1, porosity 90\%; pore size $100 \mu \mathrm{m}$ ) were pre-immersed in polylysine, and then sterilized with ethylene oxide, rinsed with phosphate-buffered saline (PBS), dried and stored in a desiccator before cell seeding.

\section{In vitro construction of engineered cartilage}

Rat chondrocytes at passage two were seeded into the scaffolds at a density of $5 \times 10^{7} \mathrm{cells} / \mathrm{cm}^{3}$, with a total of $6.4 \times 10^{6}$ cells per scaffold .To promote complete adhesion of cells to the scaffolds, the cell-scaffold constructs were then incubated at $37^{\circ} \mathrm{C}$ under $5 \% \mathrm{CO}_{2}$ for $4 \mathrm{~h}$. Then, the constructs were covered with DMEM-F12 supplemented with $10 \% \mathrm{FBS}$ and incubated at $37^{\circ} \mathrm{C}$ with $5 \% \mathrm{CO}_{2}$. The medium was replaced every 2 days and the constructs were cultured up to 6 weeks for further evaluation.

\section{Construction of a periodic mechanical stress field}

A periodic stress field encompassing the perfusion culture system with adjustable stress intensity and frequency was constructed by connecting a reciprocating intensifier pump to the air-tight cell culture device through a barrier-type pressure transducer, as described previously [7]. In an earlier study, we showed that rabbit chondrocytes subjected to stress varying from 0 to $200 \mathrm{kPa}$ at $0.1 \mathrm{~Hz}$ yielded tissue-engineered cartilage of the best quality. Accordingly, a pressure range of $0-200 \mathrm{kPa}$ and $0.1 \mathrm{~Hz}$ frequency were used in the current study.

\section{Experimental groups}

The experiment comprised two steps. In the first step, cells were pretreated with shRNA targeted to integrin $\beta 1$, wild-type integrin $\beta 1$ vector or GFP-vector (GV287). Cells were maintained under static conditions or periodic mechanical stress for $1 \mathrm{~h}$ prior to western blot analysis (ERK1/2 phosphorylation), 8 $\mathrm{h}$ prior to qPCR analysis (aggrecan and type II collagen gene expression), and then subjected to mechanical stress for $8 \mathrm{~h}$ per day for7 days prior to western blot analysis (aggrecan and type II collagen protein 


\section{Cellular Physiology Cell Physiol Biochem 2015;37:1301-1314 \begin{tabular}{ll|l} 
and Biochemistry $10.1159 / 000430253$ & Published online: October 19, 2015 & $\begin{array}{l}\text { O 2015 The Author(s). Published by S. Karger AG, Basel } \\
\text { www.karger.com/cpb }\end{array}$ \\
\hline
\end{tabular} \\ Liang et al.: Integrin $\beta 1$ Enhances Tissue-Engineered Cartilage}

expression) and 3 days prior to direct cell counting and CCK- 8 assay. All groups were incubated at $37^{\circ} \mathrm{C}$ under $5 \% \mathrm{CO}_{2}$.

In the second step, after pretreatment as described above, the different treatment groups of rat chondrocytes were seeded onto PLGA scaffolds and maintained under conditions of periodic mechanical stress for 6 weeks ( $8 \mathrm{~h}$ per day mechanical stress) prior to analysis of gross view and wet weight, GAG content, and histological and immunohistochemical assay. All groups of cells were incubated at $37^{\circ} \mathrm{C}$ under $5 \% \mathrm{CO}_{2}$.

\section{Transfection analysis}

The full length coding region of rat integrin $\beta 1$ cDNA (NM_017022) was inserted into a GV287 vector (Ubi-MCS-3FLAG-SV40-EGFP) to generate a GV287/ integrin $\beta 1$ (+) overexpression vector, with transcription initiated by the CMV promoter. Chondrocytes transfected with mock control GV287 vector served as a control. The shRNA targeting integrin $\beta 1$ (GGGCTGAAGACTACCCTAT) and negative control sequences (TTCTCCGAACGTGTCACGT) were ligated into a GV118 vector (mU6-MCS-Ubi-EGFP), respectively. After the different fragments were combined with lentivirus vectors, they were transferred into 293T cells to package lentivirus particles.

Chondrocytes were divided into three treatment groups. Each group of cells was plated at a concentration of $10^{5}$ cells/well into six-well plates and allowed to adhere for one day before transfection. Next day the cells were transfected with Lv-integrin $\beta 1$ vector, Lv-shRNA-integrin $\beta 1$ vector or control LvGFP vector in serum-free medium. Twelve hours after transfection, the media were all changed to complete medium. Three days after transfection, GFP expression was detected by fluorescence microscopy, and the expression of integrin $\beta 1$ protein was assessed by western blot analysis.

\section{Proliferation studies}

Proliferation was assessed by two different methods, specifically, direct cell counting and the CCK-8 assay.

\section{Direct cell counting}

Cells were trypsinized and counted according to published protocols [24]. Second-generation chondrocytes were seeded onto glass slides $(25 \mathrm{~mm} \times 25 \mathrm{~mm})$ coated with type II collagen at a density of $10^{5}$ cells and randomly divided into different groups, each comprising six glass slides. Experiments were performed when cells had reached approximately $\sim 70-80 \%$ confluence. Chondrocytes were cultured for 3 days under non-pressure conditions or periodic mechanical stress for $8 \mathrm{~h}$ per day, prior to direct cell counting. Cells were trypsinized and counted, and the cell number was determined by counting cells from each glass slide independently. Experiments were repeated five times.

CCK-8 assay

Cell proliferation was determined using CCK-8 solution according to the manufacturer's (Dojindo Lab., Kumamoto, Japan) instructions [25]. Cells were added to $10 \mu \mathrm{L}$ of CCK-8 solution in each well of five 96-well plates $\left(\mathrm{n}=5\right.$ ) and incubated for $4 \mathrm{~h}$ at $37^{\circ} \mathrm{C}$. The absorbance of each well was determined at $450 \mathrm{~nm}$ using a microplate reader.

\section{Quantitative real-time PCR ( $($ PCR) analysis}

Total RNA was extracted using RNAiso Plus and reverse-transcribed into cDNA using the PrimeScript RT Reagent Kit, according to the manufacturer's protocol (Shiga, Japan). qPCR analysis was performed with the LightCycler System (Roche Diagnostics, Basel, Switzerland) using SYBR Premix Ex Taq II, as described previously [26]. The reaction was performed in a $20 \mu \mathrm{L}$ mixture containing $2 \mu \mathrm{L}$ cDNA. Each cDNA sample was amplified using specific primers (Table 1, TaKaRa) under the following cycling conditions: $30 \mathrm{~s}$ initial denaturation at $95^{\circ} \mathrm{C}$, followed by 40 cycles at $95^{\circ} \mathrm{C}$ for $5 \mathrm{~s}$ and $60^{\circ} \mathrm{C}$ for $20 \mathrm{~s}$. Gene expression for AGC and Col2 was normalized against that for GAPDH.

Western blot analysis

Total protein was prepared and western blot analyses were performed as described previously [27]. Total protein was prepared using RIPA buffer, and the Bradford assay was employed to determine protein concentrations. Protein samples were resolved using SDS-PAGE, and transferred to nitrocellulose membranes. Following blocking for $1 \mathrm{~h}$ with $5 \%$ skimmed milk in TBST, membranes were incubated with 


\section{Cellular Physiology Cell Physiol Biochem 2015;37:1301-1314 \begin{tabular}{ll|l} 
and Biochemistry $10.1159 / 000430253$ & $\begin{array}{l}\text { @ 2015 The Author(s). Published by S. Karger AG, Basel } \\
\text { www.karger.com/cpb }\end{array}$ \\
\hline
\end{tabular} \\ Liang et al.: Integrin $\beta 1$ Enhances Tissue-Engineered Cartilage}

Table 1. Primer sequences and product sizes of real-time PCR. F: forward; R: reverse; AS: amplicon size; bp: base pairs; AT: annealing temperature

\begin{tabular}{llcc}
\hline Genes & Sequence of primers $\left(5^{\prime}-3^{\prime}\right)$ & AS(bp) & AT(degrees) \\
\hline Aggrecan & $\begin{array}{l}\text { F GAAGTGATGCATGGCATTGAGG } \\
\text { R ATGATGGCGCTGTTCTGAAGG }\end{array}$ & 146 & 60 \\
Type II collagen & $\begin{array}{l}\text { F GAGGGCAACAGCAGGTTCAC } \\
\text { R TGTGATCGGTACTCGATGATGG }\end{array}$ & 95 & 60 \\
GAPDH & $\begin{array}{l}\text { F GGCACAGTCAAGGCTGAGAATG } \\
\text { R ATGGTGGTGAAGACGCCAGTA }\end{array}$ & 143 & 60 \\
\hline
\end{tabular}

antibodies (1:1,000 dilutions for all antibodies) overnight at $4^{\circ} \mathrm{C}$. Blots were incubated with horseradish peroxidase-conjugated secondary antibody at ambient temperature for $1 \mathrm{~h}$, and colors were subsequently developed with ECL. Results were scanned using a gel imaging system (UVP LLC, Upland, CA) and measured using Gel-Pro Analyzer software (Media Cybernetics, Rockville, MD).

\section{Gross View and Wet Weight}

The constructs harvested from Lv-integrin $\beta 1$, Lv-shRNA-integrin $\beta 1$ and Lv-GFP groups were continuously recorded by photography to evaluate macroscopic morphology. At the end of the 6-week culture period, differences in wet weight between specimens were assessed using an electronic balance.

\section{GAG Content}

After 6 weeks in culture, tissues from each group were collected and GAG content was recorded. The samples were rinsed with double-distilled $\mathrm{H}_{2} \mathrm{O}$, lyophilized for $12 \mathrm{~h}$, then $1 \mathrm{~mL}$ cold $\mathrm{H}_{2} \mathrm{O}$ was added and the solution was incubated at $4^{\circ} \mathrm{C}$ in a microcentrifuge tube overnight. After lysing by repeated cycles of freeze-thawing and sonication, samples were centrifuged at 8,000 rpm for $3 \mathrm{~min}$. The supernatants were collected and $25 \mathrm{~mL}$ of the supernatant was mixed with $5 \mathrm{~mL} \mathrm{NaCl}(2.3 \mathrm{M})$ and $200 \mathrm{~mL}$ 9-dimethylmethylene blue (DMMB) chloride solution (Sigma-Aldrich). Absorption at $520 \mathrm{~nm}$ was then measured using a spectrophotometer. A standard curve of known concentrations of chondroitin sulfate B (Sigma-Aldrich) was run concurrently and used to determine unknown sample concentrations.

\section{Histological and immunohistochemical analysis}

For histological examination, the engineered cartilage samples were washed with PBS and fixed in formalin. They were then embedded in paraffin and cut into $4-\mu \mathrm{m}$ thick sections. The sections were stained with hematoxylin-eosin (HE) and safranin-0. For immunohistochemical analysis of type II collagen, to block the endogenous peroxidase, the deparaffinized sections were incubated with $\mathrm{H}_{2} \mathrm{O}_{2}$ and methanol for 10 min and then incubated for 30 min with serum blocking solution. The sections were then incubated with the primary antibodies (Abcam, ab34712, 1:200 dilutions for all antibodies) for $1 \mathrm{~h}$, followed by incubation with the horseradish peroxidase (HRP)-conjugated anti-rabbit secondary antibodies for $30 \mathrm{~min}$. To visualize the bound antibodies, the sections were incubated with DAB for $10 \mathrm{~min}$. All of the incubations were performed at room temperature.

\section{Statistical analysis}

Statistical analyses were performed using SPSS 14.0 software, and results are expressed as mean \pm standard deviation. Student's unpaired $t$-test and one-way analysis of variance (ANOVA), followed by post-hoc Fisher's least significance difference (LSD) test, were used to determine statistical significance. A $P$-value $<0.05$ was considered significant.

\section{Results}

\section{Transfection of lentivirus vectors}

To investigate the role of integrin $\beta 1$ up-regulation in periodic mechanical stressinduced chondrocyte proliferation and matrix synthesis, we employed lentivirus vector Lv-integrin $\beta 1$ to-up-regulate integrin $\beta 1$ expression and constructed lentivirus vector Lv-shRNA- integrin $\beta 1$ to suppress integrin $\beta 1$ expression, while the empty vector Lv-GFP 


\section{Cellular Physiology Cell Physiol Biochem 2015;37:1301-1314 \begin{tabular}{ll|l} 
DOI: 10.1159/000430253 & O 2015 The Author(s). Published by S. Karger AG, Basel
\end{tabular}

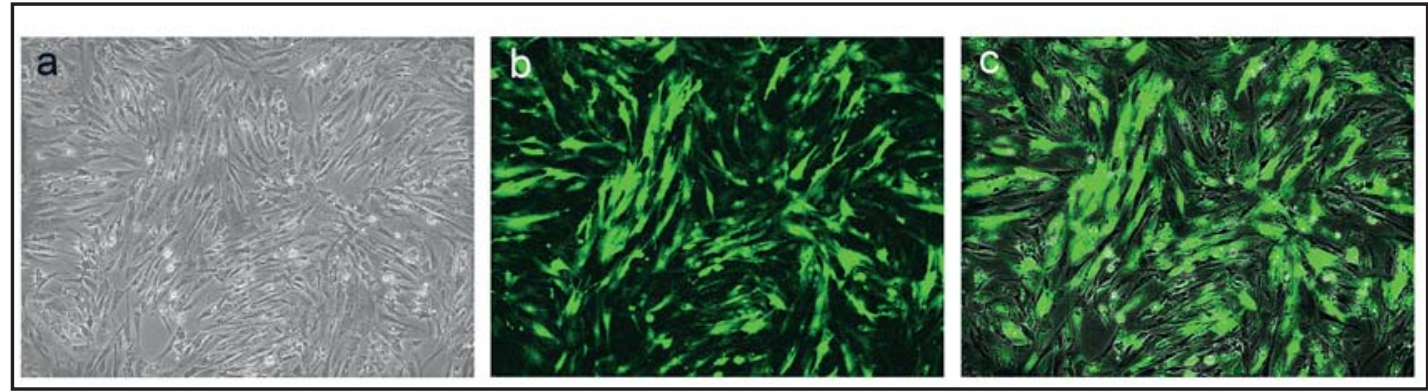

Fig. 1. The transfection efficiency of chondrocytes was estimated by light microscopy (a) and fluorescence microscopy (b). Comparing cells in bright field and fluorescent views of the same field suggested that the transfection efficiency was more than $80 \%$ (c).

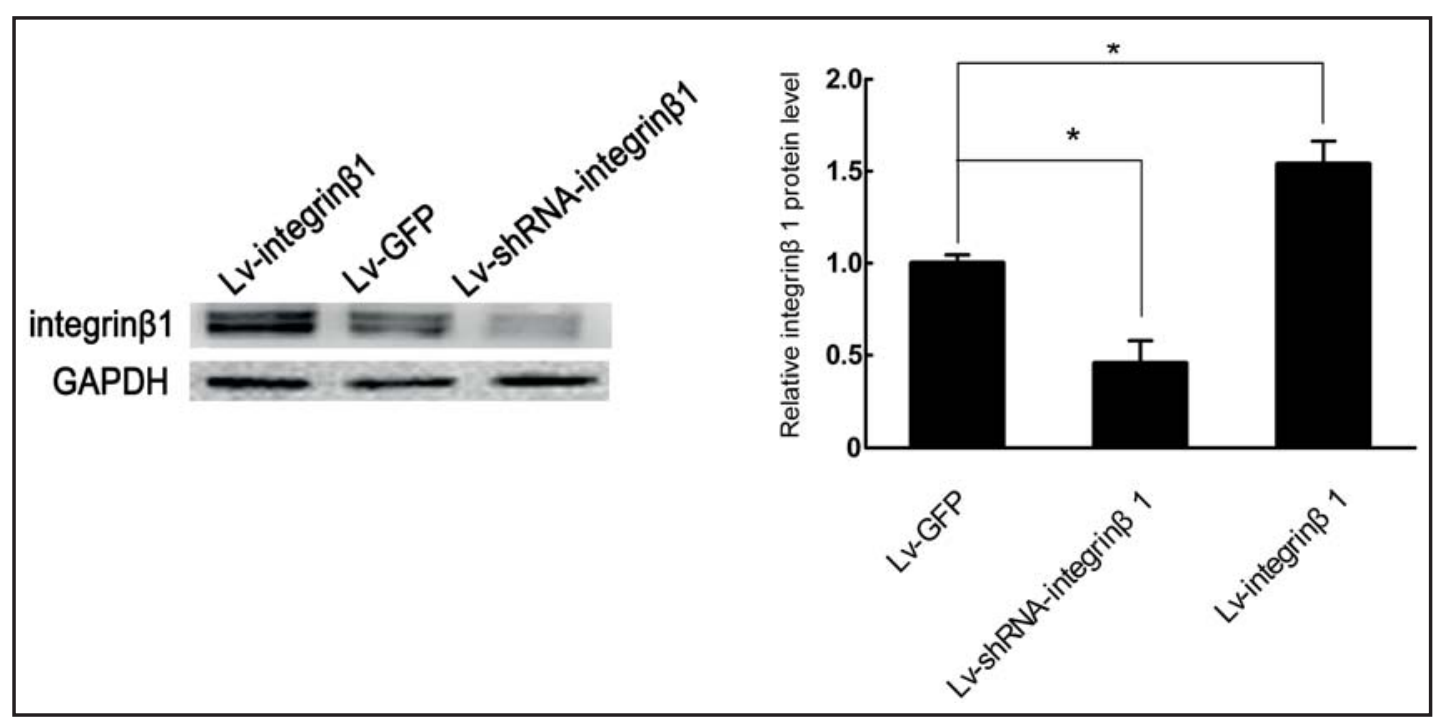

Fig. 2. The effects of transfection with Lv-GFP, Lv-shRNA-integrin $\beta 1$ and Lv-integrin $\beta 1$ vectors on the relative protein expression of integrin $\beta 1$. Chondrocytes were pretreated with shRNA targeted to integrin $\beta 1$ (Lv-shRNA-integrin $\beta 1$ ) or wild-type integrin $\beta 1$ (Lv-integrin $\beta 1$ ) or non-targeting sequences (Lv-GFP) prior to lysis and western blotting for integrin $\beta 1$ proteins. Transfection with shRNA for integrin $\beta 1$ or wild-type integrin $\beta 1$ achieved $\sim 60 \%$ reduction or $\sim 50 \%$ increase in integrin $\beta 1$ protein levels, respectively $(n=5$, $p<0.05$ for each, One-way analysis of variance (ANOVA) followed by post-hoc Fisher's least significance difference (LSD) test).

served as a control. Three days after transfection, we evaluated GFP expression in each group by fluorescence microscopy. More than $80 \%$ of chondrocytes were effectively transfected suggesting high transfection efficiency (Fig. 1).

\section{Expression of integrin $\beta 1$ protein after transfection}

The protein expression levels of integrin $\beta 1$ in each group were analyzed by Western blotting. We found that compared with the Lv-GFP group, integrin $\beta 1$ expression was significantly increased in the Lv-integrin $\beta 1$ group ( $p<0.05$ for each, Fig. $2, \mathrm{n}=5$ ), while LvshRNA-integrin $\beta 1$ transfection markedly abolished integrin $\beta 1$ expression in the Lv-shRNAintegrin $\beta 1$ group ( $p<0.05$ for each, Fig. $2, \mathrm{n}=5$ ).

Effect of integrin $\beta 1$-upregulation on chondrocyte proliferation and matrix synthesis under periodic mechanical stress

After pretreatment with Lv-integrin $\beta 1$, Lv-shRNA-integrin $\beta 1$ and Lv-GFP plasmids, proliferation and matrix synthesis of chondrocytes exposed to periodic mechanical stress or 


\section{Cellular Physiology Cell Physiol Biochem 2015;37:1301-1314 \begin{tabular}{l|l} 
DOI: 10.1159/000430253 & () 2015 The Author(s). Published by S. Karger AG, Basel
\end{tabular}

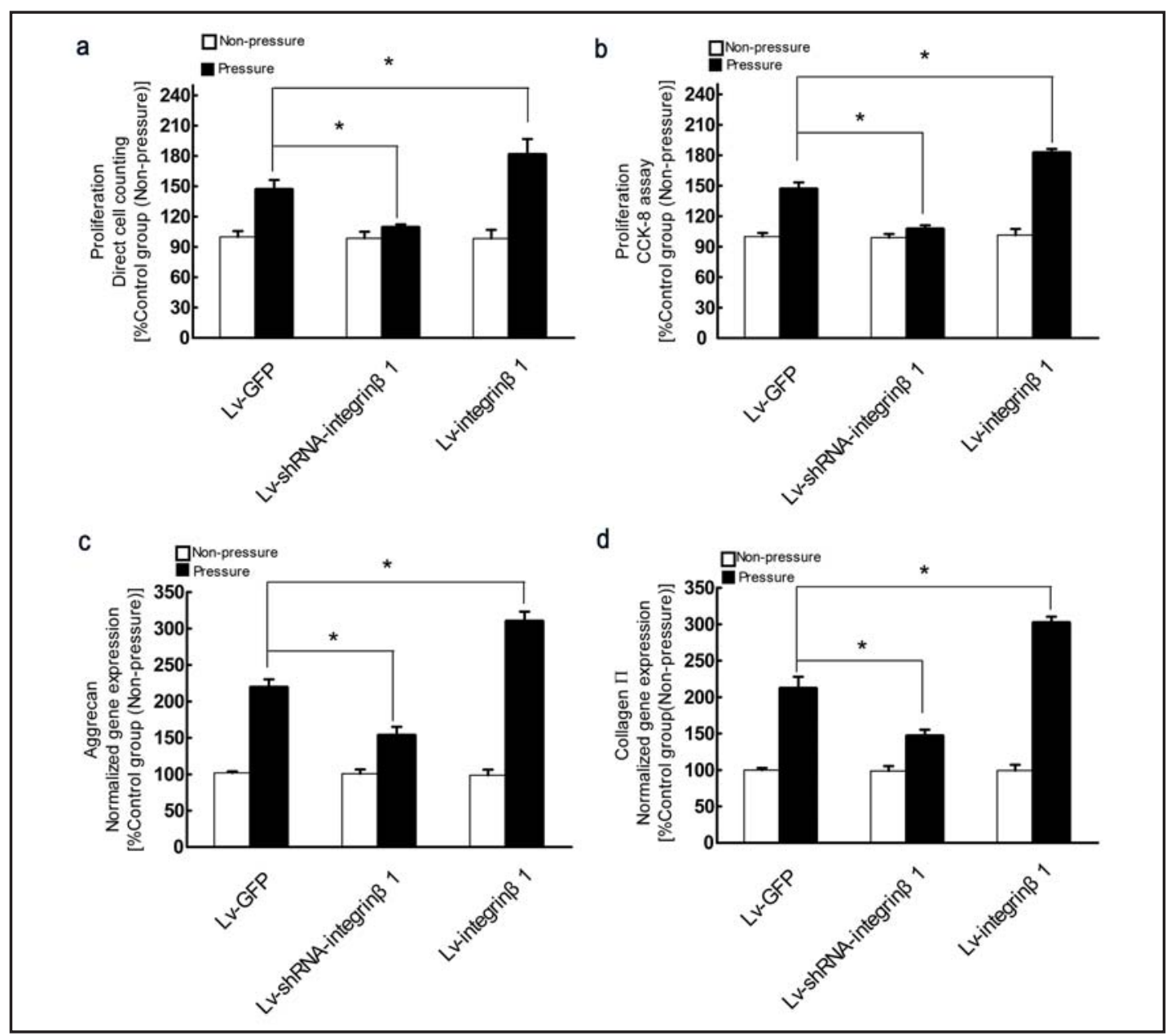

Fig. 3. Effects of inhibition or up-regulation of integrin $\beta 1$ on proliferation and gene expression of aggrecan and type II collagen in chondrocytes subjected to periodic mechanical stress or under static conditions. After pretreatment with control vehicle (Lv-GFP) or shRNA targeted to integrin $\beta 1$ (Lv-shRNA-integrin $\beta 1$ ) or wild-type integrin $\beta 1$ (Lv- integrin $\beta 1$ ), rat chondrocytes were cultured for $3 \mathrm{~d}$ under static conditions or conditions of periodic mechanical stress for $8 \mathrm{~h}$ per day prior to proliferation studies, or for $8 \mathrm{~h}$ with or without periodic mechanical stress prior to analysis of gene expression of aggrecan and type II collagen. Chondrocyte proliferation was analyzed using direct cell counting (a) and CCK-8 assay (b). Gene expression of aggrecan (c) and type II collagen (d) was analyzed using qPCR assay. Chondrocyte proliferation and gene expressions of aggrecan and type II collagen in Lv-integrin $\beta 1$ groups and Lv-shRNA-integrin $\beta 1$ groups were significantly increased and diminished, respectively, in comparison with Lv-GFP groups in response to periodic mechanical stress. ( $\mathrm{n}=5, p<0.05$ for each, analyzed by one-way analysis of variance (ANOVA) followed by post-hoc Fisher's least significance difference (LSD) test). Under static conditions, there were no differences among these groups. ( $\mathrm{n}=5, p>0.05$ for each, analyzed by one-way ANOVA followed by posthoc Fisher's LSD test).

under static conditions were examined. We found that stimulation by periodic mechanical stress strongly increased chondrocyte proliferation as well as aggrecan and type II collagen gene and protein expression in the Lv-integrin $\beta 1$ group compared to the Lv-GFP group ( $p<$ 0.05 for each, Fig. $3,4, n=5$ ), while the Lv-shRNA-integrin $\beta 1$ group showed the opposite results $(p<0.05$ for each, Fig. 3, 4, n=5). However, when cultured under static conditions, chondrocyte proliferation and matrix synthesis were not affected by transfection with Lvintegrin $\beta 1$ or Lv-shRNA- integrin $\beta 1$ ( $p>0.05$ for each, Fig. 3, 4, n=5). 


\section{Cellular Physiology Cell Physiol Biochem 2015;37:1301-1314

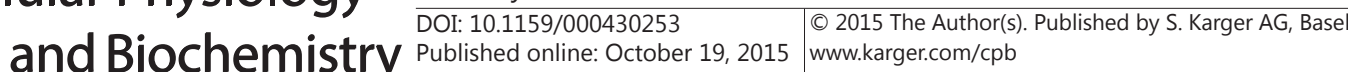
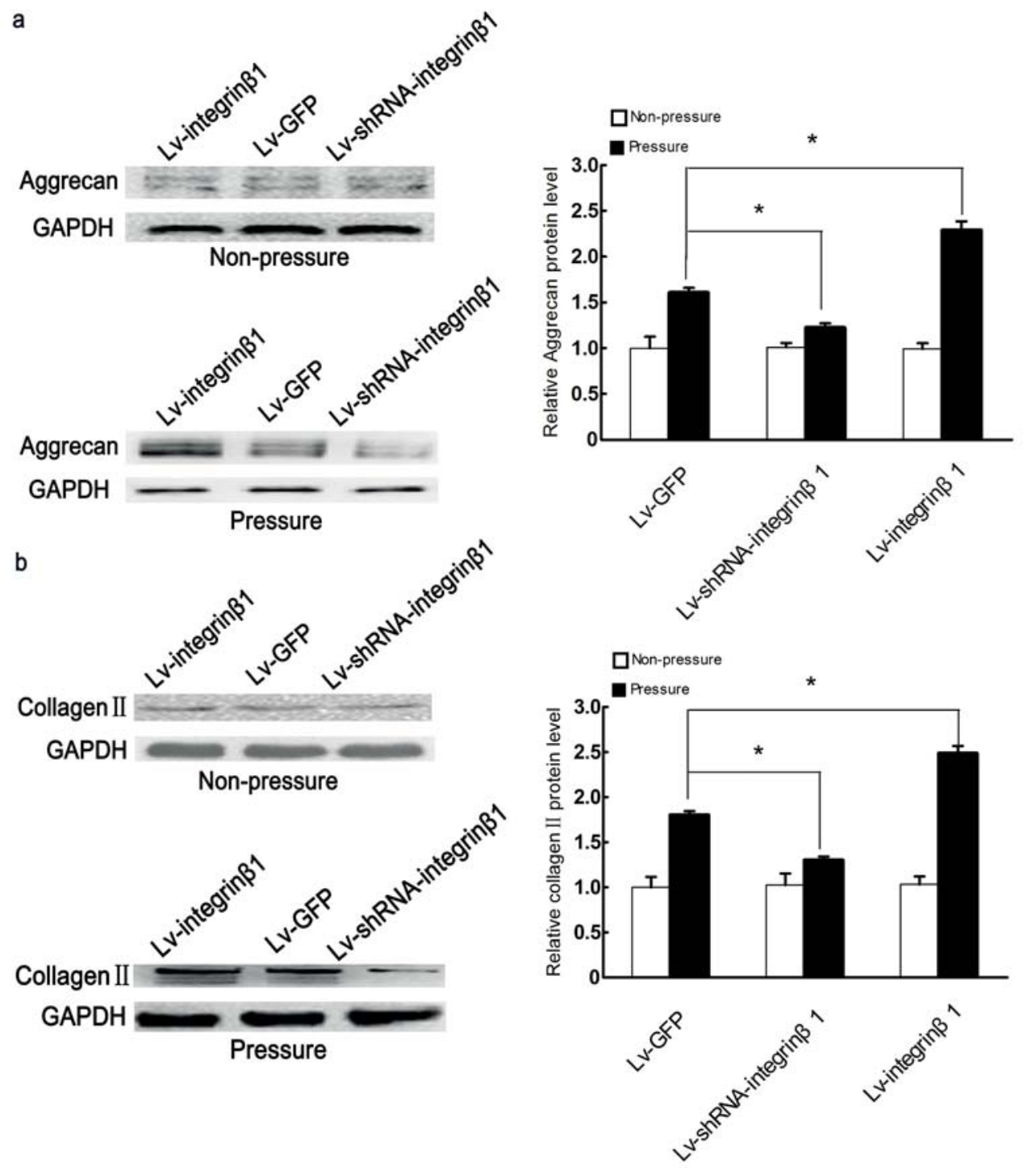

Fig. 4. Effects of inhibition or up-regulation of integrin $\beta 1$ on protein expression of aggrecan and type II collagen in response to periodic mechanical stress or under static conditions. After pretreatment with control vehicle (Lv-GFP) or shRNA targeted to integrin $\beta 1$ (Lv-shRNA-integrin $\beta 1$ ) or wild-type integrin $\beta 1$ (Lv- integrin $\beta 1$ ), rat chondrocytes were cultured for $7 \mathrm{~d}$ under static conditions or conditions of periodic mechanical stress for $8 \mathrm{~h}$ per day prior to analysis of protein expression of aggrecan and type II collagen. Protein expression of aggrecan (a) and type II collagen (b) were analyzed using western blot assay. Protein expression of aggrecan and type II collagen in Lv-integrin $\beta 1$ groups and Lv-shRNA-integrin $\beta 1$ groups were significantly elevated and blocked, respectively, in comparison with Lv-GFP groups in response to periodic mechanical stress. ( $\mathrm{n}=5, p<0.05$ for each, analyzed by one-way ANOVA followed by post-hoc Fisher's LSD test). Under static conditions, there were no differences among these groups. ( $\mathrm{n}=5, P>0.05$ for each, analyzed by one-way ANOVA followed by post-hoc Fisher's LSD test).

Effects of integrin $\beta 1$ up-regulation on periodic mechanical stress-induced ERK1/2 phosphorylation

To clarify the specific role of integrin $\beta 1$ up-regulation in periodic mechanical stressinduced ERK1/2 phosphorylation, we transfected the cells with Lv-integrin $\beta 1$, Lv-shRNAintegrin $\beta 1$ or Lv-GFP plasmids. We observed that ERK1/2 activation in the Lv-shRNA-integrin 


\section{Cellular Physiology Cell Physiol Biochem 2015;37:1301-1314 \begin{tabular}{ll|l} 
and Biochemistry $10.1159 / 000430253$ & $\begin{array}{l}\text { DOblished online: October 19, } 2015 \\
\text { Puthw.karger.com/cpb }\end{array}$ \\
\hline
\end{tabular}

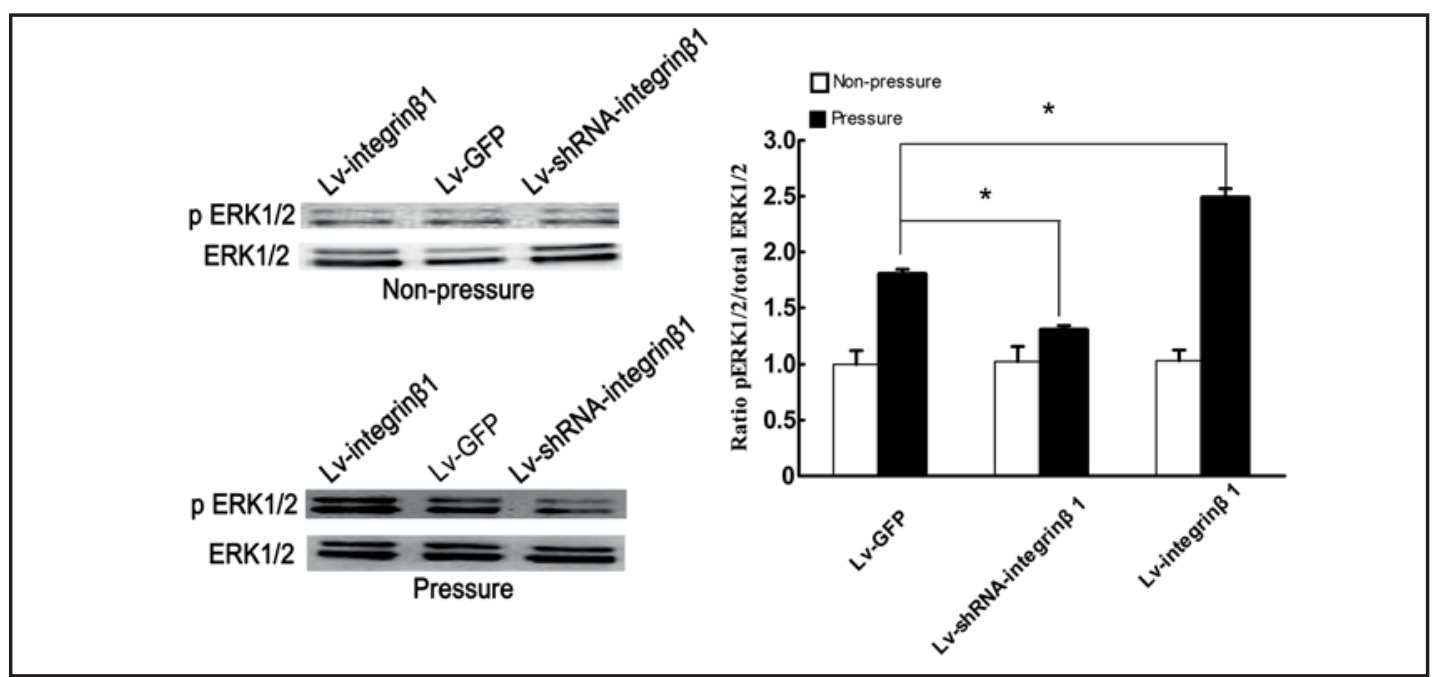

Fig. 5. Effects of inhibition or up-regulation of integrin $\beta 1$ on the expression and phosphorylation of ERK1/2 under conditions of periodic mechanical stress or static conditions. After pretreatment with control vehicle (Lv-GFP) or shRNA targeted to integrin $\beta 1$ (Lv-shRNA-integrin $\beta 1$ ) or wild-type integrin $\beta 1$ (Lv-integrin $\beta 1)$, rat chondrocytes were cultured for $1 \mathrm{~h}$ under static conditions or conditions of periodic mechanical stress. The expression and phosphorylation levels of ERK1/2 were detected by western blotting. Optical density values are represented as a histogram $(\mathrm{n}=5, *, p<0.05$ for each). The images shown are from a representative western blot. The phosphorylation levels of ERK1/2-Thr ${ }^{202} / \mathrm{Tyr}^{204}$ in Lv-integrin $\beta 1$ groups and Lv-shRNA-integrin $\beta 1$ groups were significantly increased and reduced, respectively, in comparison with Lv-GFP groups in response to periodic mechanical stress. ( $\mathrm{n}=5, p<0.05$ for each, analyzed by one-way ANOVA followed by post-hoc Fisher's LSD test). Under static conditions, there were no differences among these groups. ( $\mathrm{n}=5, p>0.05$ for each, analyzed by one-way ANOVA followed by post-hoc Fisher's LSD test).

$\beta 1$ group and the Lv-integrin $\beta 1$ group were relatively reduced or increased, respectively, compared with the Lv-GFP group, when exposed to periodic mechanical stress $(p<0.05$ for each, Fig. 5, n=5), whereas stationary culture did not affect ERK1/2 activation ( $p>0.05$ for each, Fig. 5, n=5).

\section{Gross view, wet weight and GAG content}

After 6 weeks of culture under periodic mechanical stress, we recorded differences in the gross view and size, wet weight and GAG content of the in vitro constructed cartilage to evaluate the effects of Lv-integrin $\beta 1$, Lv-GFP or Lv-shRNA-integrin $\beta 1$ transfection on 3D cartilage formation. Our results showed that cartilage-like tissue was formed in all three groups, but a marked declining trend was observed in constructed cartilage size among Lvintegrin $\beta 1$, Lv-GFP and Lv-shRNA-integrin $\beta 1$ groups (Fig. 6a). The wet weight measurement showed an increase of wet weight from the Lv-shRNA-integrin $\beta 1$ group, Lv-GFP group, to the Lv-integrin $\beta 1$ group ( $p<0.05$ for each, Fig. $6 b, n=5$ ). GAG content measurement in the Lv-shRNA-integrin $\beta 1$, Lv-GFP and Lv-integrin $\beta 1$ groups was $2.99 \pm 0.26 \mathrm{mg} / \mathrm{g}, 5.96 \pm 0.35$ $\mathrm{mg} / \mathrm{g}$ and $9.13 \pm 1.00 \mathrm{mg} / \mathrm{g}$, respectively, further supporting these findings $(p<0.05$ for each, Fig. 6c, $n=5$ ).

\section{Histological and immunohistochemical staining}

We further examined the engineered cell/scaffold constructs formed under periodic mechanical stress by staining with HE and Safranin-O as well as immunohistochemical staining with type II collagen. Typical cartilaginous metachromasia of the engineered tissues was observed. Safranin O staining reflected GAG content. Our results revealed that in response to periodic mechanical stress, more round chondrocyte-like cells with surrounding 


\section{Cellular Physiology Cell Physiol Biochem 2015;37:1301-1314 \begin{tabular}{ll|l|} 
DOI: 10.1159/000430253 & $\begin{array}{l}\text { O } 2015 \text { The Author(s). Published by S. Karger AG, Base } \\
\text { www.karger.com/cpb }\end{array}$ \\
\hline
\end{tabular} \\ Liang et al.: Integrin $\beta 1$ Enhances Tissue-Engineered Cartilage}

Fig. 6. Effects of inhibition or up-regulation of integrin $\beta 1$ on gross view, wet weight and GAG content of in vitro engineered tissue under conditions of periodic mechanical stress. After pretreatment with control vehicle (Lv-GFP) or shRNA targeted to integrin $\beta 1$ (Lv-shRNA-integrin $\beta 1$ ) or wild-type integrin $\beta 1$ (Lv-integrin $\beta 1$ ), cell-scaffold constructs were cultured for 6 weeks under conditions of periodic mechanical stress prior to gross view (a), wet weight (b) and GAG content studies (c). Results of wet weight and GAG content are shown in the histogram. All three groups formed cartilage-like tissue, but a mar-

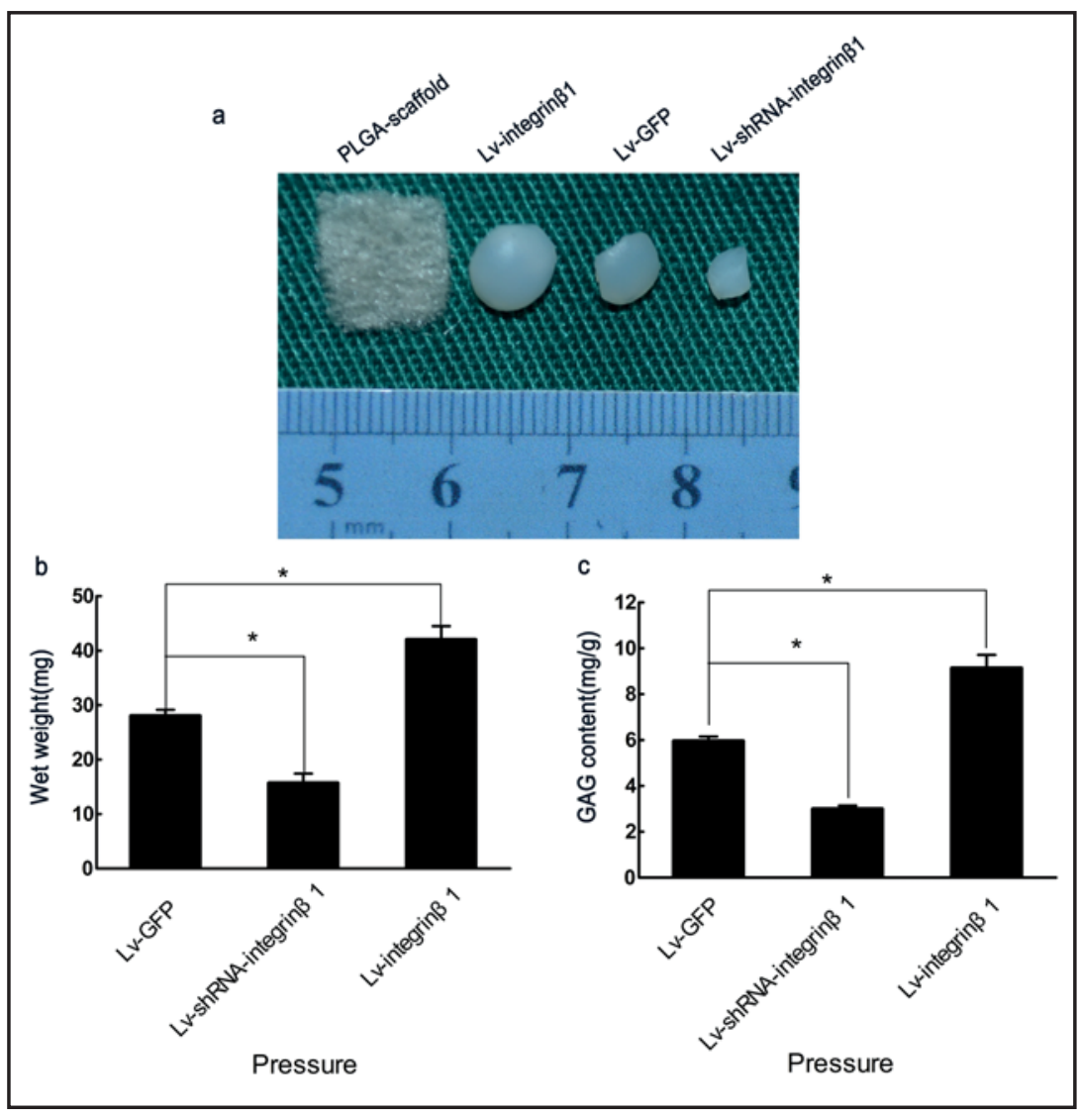
kedlydecliningtrend was observedinthesizeofcartilageconstructsamongLv-integrin $\beta 1, L v-G F P a n d L v-s h R N A$ integrin $\beta 1$ groups. ( $\mathrm{n}=5, p<0.05$ for each, analyzed by one-way ANOVA followed by post-hoc Fisher's LSD test). Wet weight and GAG content increased gradually from Lv-shRNA-integrin $\beta 1$, Lv-GFP to Lv-integrin $\beta 1$ groups. ( $\mathrm{n}=5, p<0.05$ for each, analyzed by one-way ANOVA followed by post-hoc Fisher's LSD test).

lacunae could be found in the Lv-integrin $\beta 1$ group compared to the Lv-GFP group while the Lv-shRNA-integrin $\beta 1$ group showed the opposite effect (Fig. 7a-c). Safranin 0 staining in the Lv-integrin $\beta 1$ group showed stronger staining than that in the Lv-GFP group, while the Lv-shRNA-integrin $\beta 1$ group appeared the most weakly stained under periodic mechanical stress (Fig. 7d-f). Immunohistochemical staining with type II collagen showed a similar pattern among these three groups (Fig. 7g-i).

\section{Discussion}

Periodic mechanical stress plays a pivotal role in cartilage tissue engineering, therefore exploring the signaling molecules involved in the chondrocytic mitogenic response to periodic mechanical stimulation could provide a theoretical basis for further enhancing the quality of tissue engineered cartilage. Integrins are known to be the most important mechanoreceptor in various cell types [11,28,29], and the results of our previous studies revealed that periodic mechanical stress-induced chondrocyte proliferation and matrix synthesis are partly mediated by the integrin $\beta 1$-ERK1/2 signal cascade [7-10].

Previous studies regarding the roles of integrins in signaling pathways mainly involved detecting various cellular biological effects after integrin inhibition [30-32]. We have demonstrated that chondrocyte proliferation and matrix synthesis, as well as phosphorylation of ERK1/2, are all significantly reduced after integrin $\beta 1$ depletion [9]. However, up to now, no data have directly linked integrin $\beta 1$ up-regulation to cell behavior 


\section{Cellular Physiology Cell Physiol Biochem 2015;37:1301-1314 \begin{tabular}{ll|l} 
and Biochemistry & $\begin{array}{l}\text { DOI: 10.1159/000430253 } \\
\text { Published online: October 19, } 2015\end{array}$ & $\begin{array}{l}\text { C } 2015 \text { The Author(s). Published by S. Karger AG, Basel } \\
\text { www.karger.com/cpb }\end{array}$ \\
\hline
\end{tabular} Liang et al.: Integrin $\beta 1$ Enhances Tissue-Engineered Cartilage}

Fig. 7. Effects of inhibition or up-regulation of integrin $\beta 1$ on histological and immunohistochemical staining of in vitro engineered tissue under conditions of periodic mechanical stress. After pretreatment with control vehicle (Lv-GFP) or shRNA targeted to integrin $\beta 1$ (Lv-shRNA-integrin $\beta 1$ ) or wild-type integrin $\beta 1$ (Lv-integrin $\beta 1$ ), cell-scaffold constructs were cultured for 6 weeks under conditions of periodic mechanical stress prior to he-
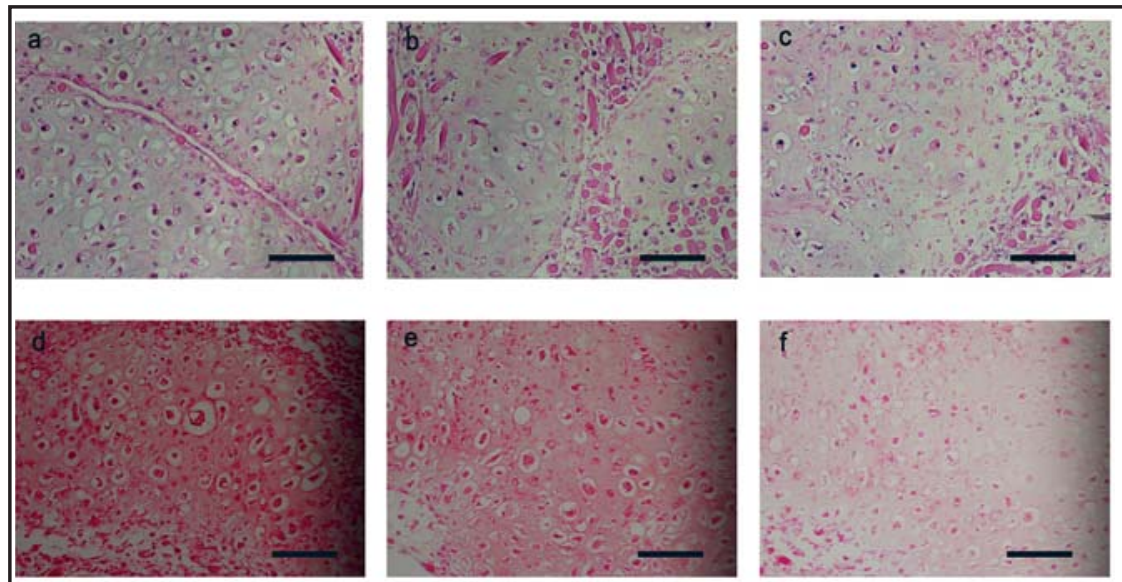

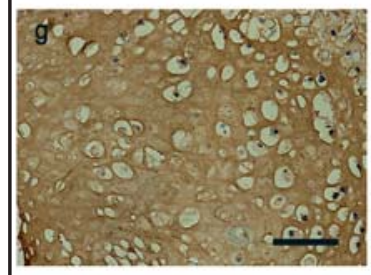

Lv-integrin $\beta 1$

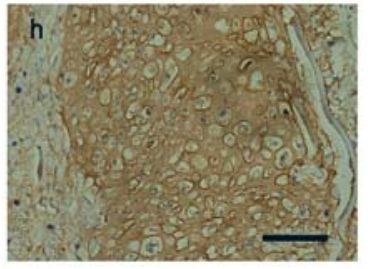

Lv-GFP

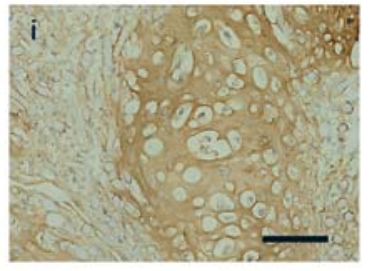

Lv-shRNA-integrin $\beta 1$

matoxylin-eosin (HE) staining (a-c), safranin-O staining (d-f) and immunohistochemical staining for collagen type II (g-i). Scale bar $25 \mu \mathrm{m}$.

and function of chondrocytes. Based on our previous results, we evaluated the hypothesis that integrin $\beta 1$ up-regulation would improve the activities and functions of chondrocytes. In our study, chondrocyte proliferation, matrix synthesis and ERK1/2 phosphorylation levels were all markedly increased upon transfection with_GFP-tagged integrin $\beta 1$ wild-type plasmid when exposed to periodic mechanical stress in chondrocyte monolayer culture. However, when cultured under static conditions, integrin $\beta 1$ up-regulation did not affect the cellular response or ERK1/2 phosphorylation in chondrocytes. These results indicate that in this context, periodic mechanical stress is the critical determinant in enhancing the quality of chondrogenesis, while integrin $\beta 1$ up-regulation is able to amplify this effect. Thus integrin $\beta 1$ up-regulation alone, without the addition of periodic mechanical stress, had no effect on the activities of chondrocytes. However, there have been contrasting findings, with some researchers reporting that under some non-mechanical stimuli, cell viability and function were also affected by integrin up-regulation in several cell types [21, 33]. For instance, an earlier study by Liu et al. showed that when integrin $\beta 4$ was up-regulated in airway epithelial cells, cell proliferation ability and anti-oxidation ability were significantly enhanced during wound repair [20]. Hayashido et al. found that once integrin $\alpha \mathrm{V}$ was upregulated, type I collagen could promote squamous cell carcinoma cell proliferation and elevate ERK1/2 phosphorylation levels [34]. These results indicate that in addition to their role in mechanosensing, integrins also possess many other functions. Indeed, integrins have also been shown to be adhesion receptors that mediate the interactions between cells and ECM to regulate various biological effects in a range of cell lineages $[35,36]$. In any case, in our present study, the main role of integrin $\beta 1$ in chondrocytes was mechanosensing. Integrin $\beta 1$ up-regulation combined with periodic mechanical stress further promoted chondrocyte proliferation and matrix synthesis, possibly through enhancement of the number of mechanoceptors, thus allowing the cells to receive more mechanical stimuli. To the best of our knowledge, this is the first study to strongly implicate integrin $\beta 1$ up-regulation in enhancing chondrocyte biological roles under a setting of periodic mechanical stress. 


\section{Cellular Physiology Cell Physiol Biochem 2015;37:1301-1314 \begin{tabular}{ll|l} 
DOI: 10.1159/000430253 & $\begin{array}{l}\text { O 2015 The Author(s). Published by S. Karger AG, Basel } \\
\text { www.karger.com/cpb }\end{array}$ \\
\hline
\end{tabular} Liang et al.: Integrin $\beta 1$ Enhances Tissue-Engineered Cartilage}

In order to determine whether integrin $\beta 1$ up-regulation could improve the quality of 3D tissue-engineered cartilage constructed in vitro, gross view and wet weight, GAG content, histological and immunohistochemical staining assays were carried out. As we had already shown that when integrin $\beta 1$ was up-regulated in chondrocyte monolayer culture, compared with mock transfectants, chondrocyte proliferation and matrix synthesis only increased under conditions of periodic mechanical stress, so we only evaluated the effects of integrin $\beta 1$ up-regulation on the quality of 3D tissue-engineered cartilage constructed in vitro in the setting of periodic mechanical stress. We observed that Lv-integrin $\beta 1$ transfection significantly promoted GAG and type II collagen synthesis, further confirming that integrin $\beta 1$ up-regulation can enhance the quality of tissue-engineered cartilage formed in 3D culture exposed to periodic mechanical stress.

Although the present study demonstrates for the first time that in addition to periodic mechanical stress, integrin $\beta 1$ up-regulation can further enhance the quality of tissueengineered cartilage in both chondrocyte monolayer culture and three-dimensional culture, some limitations still exist. For example, the current investigations were only performed in vitro; the detailed and precise mechanism of integrin $\beta 1$ up-regulation in chondrocytes in vivo under periodic mechanical stress still awaits further investigation. Furthermore, the benefits of BMSCs in cartilage and bone repair were well proved, while we only focused on the roles of chondrocytes in the current investigations [37, 38].

In conclusion, compared with periodic mechanical stress alone, periodic mechanical stress plus integrin $\beta 1$ up-regulation can further promote chondrocyte proliferation and matrix synthesis and elevate ERK1/2 phosphorylation levels in chondrocyte monolayer culture, as well as promoting GAG and type II collagen accumulation in chondrocyte 3D culture. Briefly, in addition to periodic mechanical stress, integrin $\beta 1$ up-regulation could further enhance the quality of tissue-engineered cartilage.

\section{Abbreviations}

Lv (Lentivirus vector); GAG (glycosaminoglycan); ERK (extracellular signal-regulated kinase); DMSO (dimethyl sulfoxide); HRP (horseradish peroxidase); GAPDH (glyceraldehyde3-phosphate dehydrogenase); ECM (extracellular matrix).

\section{Acknowledgements}

This work was supported by the National Natural Science Foundation (grant no.: 81271986).

\section{Disclosure Statement}

The authors declare no competing interests.

\section{References}

1 Jung Y, Kim SH, Kim YH, Kim SH: The effects of dynamic and three-dimensional environments on chondrogenic differentiation of bone marrow stromal cells. Biomed Mater 2009;4:055009.

2 Akimoto T, Kawanishi M, Ushida T: mechanical stress and tissue engineering. Clin Calcium 2008;18:13131320.

3 Wang PY, Chow HH, Lai JY, Liu HL, Tsai WB: Dynamic compression modulates chondrocyte proliferation and matrix biosynthesis in chitosan/gelatin scaffolds. J Biomed Mater Res B Appl Biomater 2009;91:143152. 


\section{Cellular Physiology Cell Physiol Biochem 2015;37:1301-1314 \begin{tabular}{ll|l} 
DOI: 10.1159/000430253 & $\begin{array}{l}\text { O 2015 The Author(s). Published by S. Karger AG, Basel } \\
\text { www.karger.com/cpb }\end{array}$ \\
\hline
\end{tabular} \\ Liang et al.: Integrin $\beta 1$ Enhances Tissue-Engineered Cartilage}

4 Pingguan-Murphy B, Nawi I: Upregulation of matrix synthesis in chondrocyte-seeded agarose following sustained bi-axial cyclic loading. Clinics 2012;67:939-944.

5 Saito T, Nishida K, Furumatsu T, Yoshida A, Ozawa M, Ozaki T: Histone deacetylase inhibitors suppress mechanical stress-induced expression of runx- 2 and adamts- 5 through the inhibition of the mapk signaling pathway in cultured human chondrocytes. Osteoarthr Cartilage 2013;21:165-174.

6 De Croos JN, Jang B, Dhaliwal SS, Grynpas MD, Pilliar RM, Kandel RA: Membrane type-1 matrix metalloproteinase is induced following cyclic compression of in vitro grown bovine chondrocytes. Osteoarthr Cartilage 2007;15:1301-1310.

7 Nong L, Yin G, Ren K, Tang J, Fan W: Periodic mechanical stress enhances rat chondrocyte area expansion and migration through src-plcgamma1-erk1/2 signaling. Eur J Cell Biol 2010;89:705-711.

8 Ren K, Ma Y, Huang Y, Liang W, Liu F, Wang Q, Cui W, Liu Z, Yin G, Fan W: Periodic mechanical stress activates mek1/2-erk1/2 mitogenic signals in rat chondrocytes through src and plcgamma1. Braz J Med Biol Res 2011;44:1231-1242.

9 Ren K, Liu F, Huang Y, Liang W, Cui W, Wang Q Fan W: Periodic mechanical stress activates integrinbeta1dependent src-dependent plcgamma1-independent rac1 mitogenic signal in rat chondrocytes through erk1/2. Cell Physiol Biochem 2012;30:827-842.

10 Liang W, Ren K, Liu F, Cui W, Wang Q, Chen Z, Fan W: Periodic mechanical stress stimulates the fak mitogenic signal in rat chondrocytes through erk1/2 activity. Cell Physiol Biochem 2013;32:915-930.

11 Israeli-Rosenberg S, Chen C, Li R, Deussen DN, Niesman IR, Okada H, Patel HH, Roth DM, Ross RS: Caveolin modulates integrin function and mechanical activation in the cardiomyocyte. FASEB J 2015;29:374-384.

12 Sanz-Ramos P, Mora G, Ripalda P, Vicente-Pascual M, Izal-Azcarate I: Identification of signalling pathways triggered by changes in the mechanical environment in rat chondrocytes. Osteoarthr Cartilage 2012;20:931-939.

13 Luo CW, Wu CC, Ch'ang HJ: Radiation sensitization of tumor cells induced by shear stress: The roles of integrins and fak. Biochim Biophys Acta 2014;1843:2129-2137.

14 Whitney NP, Lamb AC, Louw TM, Subramanian A: Integrin-mediated mechanotransduction pathway of lowintensity continuous ultrasound in human chondrocytes. Ultrasound Med Biol 2012;38:1734-1743.

15 Spiteri C, Raizman I, Pilliar RM, Kandel RA: Matrix accumulation by articular chondrocytes during mechanical stimulation is influenced by integrin-mediated cell spreading. J Biomed Mater Res A 2010;94:122-129.

16 Holledge MM, Millward-Sadler SJ, Nuki G, Salter DM: Mechanical regulation of proteoglycan synthesis in normal and osteoarthritic human articular chondrocytes--roles for alpha5 and alphavbeta5 integrins. Biorheology 2008;45:275-288.

17 Chowdhury TT, Salter DM, Bader DL, Lee DA: Integrin-mediated mechanotransduction processes in tgfbetastimulated monolayer-expanded chondrocytes. Biochem Bioph Res Co 2004;318:873-881.

18 Tanaka N, Ikeda Y, Yamaguchi T, Furukawa H, Mitomi H, Nakagawa T, Tohma S, Fukui N: Alpha5beta1 integrin induces the expression of noncartilaginous procollagen gene expression in articular chondrocytes cultured in monolayers. Arthritis Res Ther 2013;15:R127.

19 Pulai JI, Del Carlo M, Jr., Loeser RF: The alpha5beta1 integrin provides matrix survival signals for normal and osteoarthritic human articular chondrocytes in vitro. Arthritis Rheum 2002;46:1528-1535.

20 Liu C, Liu HJ, Xiang Y, Tan YR, Zhu XL, Qin XQ: Wound repair and anti-oxidative capacity is regulated by itgb4 in airway epithelial cells. Mol Cell Biochem 2010;341:259-269.

21 Hu HM, Yang L, Wang Z, Liu YW, Fan JZ, Fan J, Liu J, Luo ZJ: Overexpression of integrin a2 promotes osteogenic differentiation of hbmscs from senile osteoporosis through the erk pathway. Int J Clin Exp Patho 2013;6:841-852.

22 Cheng J, Zhang J, Merched A, Zhang L, Zhang P, Truong L, Boriek AM, Du J: Mechanical stretch inhibits oxidized low density lipoprotein-induced apoptosis in vascular smooth muscle cells by up-regulating integrin alphavbeta3 and stablization of pinch-1. J Biol Chem 2007;282:34268-34275.

23 Seguin CA, Bernier SM: Tnfalpha suppresses link protein and type II collagen expression in chondrocytes: Role of mek1/2 and nf-kappab signaling pathways. J Cell Physiol 2003;197:356-369.

24 Chaturvedi LS, Marsh HM, Shang X, Zheng Y, Basson MD: Repetitive deformation activates focal adhesion kinase and erk mitogenic signals in human caco-2 intestinal epithelial cells through src and rac1. J Biol Chem 2007;282:14-28. 


\section{Cellular Physiology Cell Physiol Biochem 2015;37:1301-1314 \begin{tabular}{l|l|l} 
10.1159/000430253 & ( ) 2015 The Author(s). Published by S. Karger AG, Basel
\end{tabular} and Biochemistry Published online: October 19, 2015 www.karger.com/cpb}

Liang et al.: Integrin $\beta 1$ Enhances Tissue-Engineered Cartilage

25 Bae JY, Han DW, Wakitani S, Nawata M, Hyon SH: Biological and biomechanical evaluations of osteochondral allografts preserved in cold storage solution containing epigallocatechin gallate. Cell Transplant 2010;19:681-689.

26 Kloesch B, Liszt M, Steiner G, Broll J: Inhibitors of p38 and erk1/2 mapkinase and hydrogen sulphide block constitutive and il-1beta-induced il-6 and il-8 expression in the human chondrocyte cell line c-28/i2. Rheumatol Int 2012;32:729-736.

27 Wang P, Cao X, Nagel DJ, Yin G: Activation of ask1 during reperfusion of ischemic spinal cord. Neurosci Lett 2007;415:248-252.

28 Zhou Y, Millward-Sadler SJ, Lin H, Robinson H, Goldring M, Salter DM, Nuki G: Evidence for jnk-dependent up-regulation of proteoglycan synthesis and for activation of jnk1 following cyclical mechanical stimulation in a human chondrocyte culture model. Osteoarthr Cartilage 2007;15:884-893.

29 Takahashi I, Onodera K, Sasano Y, Mizoguchi I, Bae JW, Mitani H, Kagayama M, Mitani H: Effect of stretching on gene expression of beta1 integrin and focal adhesion kinase and on chondrogenesis through cellextracellular matrix interactions. Eur J Cell Biol 2003;82:182-192.

30 Kaneko K, Ito M, Naoe Y, Lacy-Hulbert A, Ikeda K: Integrin alphav in the mechanical response of osteoblast lineage cells. Biochem Bioph Res Co 2014;447:352-357.

31 Thi MM, Suadicani SO, Schaffler MB, Weinbaum S, Spray DC: Mechanosensory responses of osteocytes to physiological forces occur along processes and not cell body and require alphavbeta3 integrin. Proc Natl Acad Sci U S A 2013;110:21012-21017.

32 Spiteri CG, Young EW, Simmons CA, Kandel RA, Pilliar RM: Substrate architecture and fluid-induced shear stress during chondrocyte seeding: Role of alpha5beta1 integrin. Biomaterials 2008;29:2477-2489.

33 Fu S, Fan L, Pan X, Sun Y, Zhao H: Integrin alphav promotes proliferation by activating erk 1/2 in the human lung cancer cell line a549. Mol Med Rep 2015;11:1266-1271.

34 Hayashido Y, Kitano H, Sakaue T, Fujii T, Suematsu M, Sakurai S, Okamoto T: Overexpression of integrin alphav facilitates proliferation and invasion of oral squamous cell carcinoma cells via mek/erk signaling pathway that is activated by interaction of integrin alphavbeta8 with type collagen. Int J Oncol 2014;45:1875-1882.

35 Ellis SJ, Lostchuck E, Goult BT, Bouaouina M, Fairchild MJ, Lopez-Ceballos P, Calderwood DA, Tanentzapf G: The talin head domain reinforces integrin-mediated adhesion by promoting adhesion complex stability and clustering. Plos Genet 2014;10:e1004756.

36 Sipila K, Haag S, Denessiouk K, Kapyla J, Peters EC, Denesyuk A, Hansen U, Konttinen Y, Johnson MS, Holmdahl R, Heino J: Citrullination of collagen ii affects integrin-mediated cell adhesion in a receptorspecific manner. FASEB J 2014;28:3758-3768.

37 Diederichs S, Zachert K, Raiss P, Richter W: Regulating chondrogenesis of human mesenchymal stromal cells with a retinoic acid receptor-beta inhibitor: Differential sensitivity of chondral versus osteochondral development. Cell Physiol Biochem 2014;33:1607-1619.

38 Hu N, Wang C, Liang X, Yin L, Luo X, Liu B, Zhang H, Shui W, Nan G, Wang N, Wu N, Chen X, He Y, Wen S, Deng F, Zhang H, Liao Z, Luu HH, Haydon RC, He TC, Huang W: Inhibition of histone deacetylases potentiates bmp9-induced osteogenic signaling in mouse mesenchymal stem cells. Cell Physiol Biochem 2013;32:486498. 